\title{
STS as an approach for STEM education pedagogy
}

\author{
Jiraporn Tupsai \\ ${ }^{1}$ KhonKaen University (KKU) ,Education, Demonstration School (Suksasart), \\ KhonKaen, Thailand
}

\begin{abstract}
This study aims to seek the way to apply STEM education into science classroom. STEM is an integrating of four specific disciplines including science, technology, engineering and mathematics into interconnected learning process based on practical applications. Based on Yuenyong (2006) STS approach, social topics and/or social crises can be a part of science and technology classroom. In addition, the literatures about implementing STS approach for science teaching revealed that students had chance to practice their knowledge for real world problems. The STS unit also allowed students to improve the related skills for find solutions that could be used the process that similar process of the Engineering Design Process (EDP) of STEM education. The EDP-STS-STEM Education provided the process of EDP into the five stages of Yuenyong (2006) STS approach. Therefore, the paper provided some examples of EDP-STS-STEM Education that was used to introduce STEM education into science classroom.
\end{abstract}

Keywords:STEMeducation, EDP-STS-STEM Education.

\section{Introduction}

In the 21 st century, education undertaken the wide range of goals has been put more emphasis on STEM learning into practice in the light of development of modern education. However, the education system in Thailand today is rather exam oriented. Teaching methods in the classroom do not emphasize the pedagogy that should give the students an in-depth understanding. Although the STEM education process is recognized as a valuable strategy to build students' deep understanding of scientific content and inquiry by their own knowledge through inquiry-based exercises, current teaching methods in practice are to push students to memorize lessons that does not stimulate students' thoughts.

Recently, the government has introduced educational reform as to mainly focus on student-centered teaching strategies. This strategy should include the extent of STEM education into the reform aiming to modernize citizens with diverse skills and global competitiveness so that they can live in a knowledge-based society. It is important to prepare students with robust soft skills, such as creative thinking, imagination, and self-efficacy in the earlier stage of their education [1].

Numerous soft skills are significant not only for improving academic achievement, but also for developing their competencies, while prompting students with several individual values on future career success. An individual should have potent soft skills (e.g. leadership, teamwork, creative and critical thinking) to reach successful level in their career. Also, in real working situation, employees should be able to solve problems logically and ethically in line with organization and public interest.

Soft skills are vital elements in the work force for advancing businesses [1][2][3][6]. There are various significant soft skills and qualities to keep pace with competitive circumstances at a workplace, including, interpersonal communication, analytical and problem-solving skills, fast learning, teamwork, innovation, creativity, and adaptability to environment changes. Thus, certain soft skills (e.g.including communication, critical thinking and problem-solving, teamworking, lifelong learning and information management, entrepreneurial, moral and professional ethics, and leadership) should be implemented in teaching and highlighted in school curriculum.

Byadopting Science, Technology, Engineering and Mathematics (STEM) projects in teaching at all levels, students are continuously motivated to apply skills and knowledge from each discipline in an integrated manner. A broad agreement of STEM education 
on "the problem" and the trend to focus on improving individual classroom instruction has not led to a more seasoned understanding of the root causes of ineffective teaching and learning and the approach to plan teaching activities. One of the goals of STEM education is to improve teaching activities and develop skill higher order thinking of students in science classroom [4].

Finally, the STEM education approach is expected to be able to sharpen students' highlevel thinking skills to produce students who can become STEM experts in the future. Due to increasing interests and tendencies among students and teachers towards Science, Technology, Engineering and Mathematics (STEM) education, various approaches and teaching strategies have been proposed to provide students with the ability in the STEM fields.

\section{STS Approach and STEM Process}

Science is integrated into STEM-based lessons, meaning that students who are taught within well-designed approachwill become scientifically competent. The STEM-based lessons provide students opportunities to learn science in contexts that they understand and lead to cross-discipline connections to otherskills. Several activities commonly found in technology classrooms are potential to develop students' scientific literacy. The activities also convey students to think logically before defining a technological design to solve certain problems and constructing their thinking systematically by acquiring knowledge to seek solutions. Due to the STEM teacher's increased responsibilities, teaching Physics in actual class was observed by focusing on class activities in which integrated STS-STEM was implemented and what students could learn from those activities [3][4].

\subsection{STEM Education and Engineering Design}

The concept of an engineering design and learning of Science, Technology and Mathematics is unique to organize STEM learning. Since students attempt to learn, understand and practice skills in Science, Technology and Mathematics, they have greater opportunities to apply the knowledge in designing an invention or a STEM-based mipmapping to meet their daily problemsolving needs.

\section{(EDP) \\ 2.1.1The Engineering Design Process}

The concept of EDP is to improve students' decision making in order to develop high quality solutions and/or invention/products to solve certain problems. Thus, the main objectives of EDP are to lead students to have engineering qualities, meaning that teachers need to listen to students, and classroom environments need to change properly to enable learning through EDP, particularly, skills and abilities associated with engineering design for high school students. When EDP focusing on engineering design, combines with the widely used teaching approach of STS and STEM education. The new version of EDP-STS-STEM Education consists of nine stages is shown as below [4]:EDP-STS-STEM Teaching Strategy.

Generally, the imaginative ideas emerged from observing the flaws, or a different approach may become apparent during working on challenges. Throughout this process, students repetitively assess and challenge their ideas by repeating steps every now and then, even restarting from the beginning.

\subsubsection{Intervention EDP-STS-STEM}

\section{Education}

The ideas of the Engineering Design Process (EDP) are provided along each stage of STS approach. An intervention of EDP-STS-STEM education learning unit is designed based theoretical framework of Engineering Process Design and Yuenyong (2006) Science Technology Society (STS) approach. The ideas of learning activities, firstly, are provided regarding five stages of Yuenyong (2006) STS approach as illustrated below [4] [6][8]:

\section{EDP-STS-STEM Model}

1) Social issues challengingidentification of social issues - to identify needs or problems.

2) Research related Science and Math:the needs or problems - to develop possible solutions. 
3) Solution Design:Decision-making to select the best possible solution construct a prototype.

4) Redesign and Communication:Testing the solutions to evaluate the solutions' application redesign if needed.

5) Decision Making:Completion of decision to communicate and share about the solutions with others.

The activity plan to improve students' ideas in applying the knowledge and processes were clarified in each stage of the STS science content. The dialogues and students' tasks were also highlighted by representation the interpretation. Then, the interpretation from peer debriefing activity was used to ensure the credibility since the interpretation could be subjective, varied from the particular students.Then, students' storytelling and representation reflecting what students have learnt during their work process (i.e.designing, making, and presenting their innovation)wasinterpreted. The STS teaching instruments, including science contents, students' discussion and questions, worksheets were observed, followed by an unstructured interview. The interview and observation were to examine what and how students applied their knowledge of science, and mathematics and other related subjects as well as their process of engineer process design to develop their best solution as technology products [5][6][8][9][10][11][12][13][14][15].

Strengthening STEM initiatives is a positive and proactive step in developing specialists in line with STEM education to meet the needs of the country aiming to increase students' interest through a new learning approach. It could improve high level thinking skills to utilize practical teaching facilities and design content relevant to students' daily life to increase interest. By doing this, teachers should also be provided with training to have skills and abilities for teaching at primary school and middle schools to teach the revised curriculum, raise awareness among parents and students about STEM through national campaigns. This aspiration is expected to provide students with the opportunity to improve their skills and knowledge in the field of Science, resulting in further enhancement of their excellence in an international level [16][17].

\section{Teaching Strategies}

The EDP-STS-STEM Education is majorly concerned with the development of HOTs skills. These skills were formed upon individuals with critical thinking skills. For graduates within the EDP-STS-STEM community to remain relevant, they need to be able to continuously enhance their capacities to develop professional knowledge through thinking and reasoning, problem solving, decision making and interpersonal competence. Developing these skills are not only critical for work but also inevitably necessary to deal with the complexities of the family, community and society. Research literature has led to the exposure of the level and state of thinking skills in Thailand as well as other developing nations of the world. Literature emanating from recent studies has also revealed that students in both higher education and secondary education in Thailand lack of sufficient utilization of higher order thinking skills (HOTS). Previous studies showed that teaching and learning of HOTS starting from understanding learners' individual differences should be further encouraged [3][4][6][18][19][20] because students can construct knowledge more meaningful at their own pace [7]. Therefore, teaching strategies of the EDP-STS-STEM model as shown in Figure 2 , were introduce in the three Physics lessons as described below.

\subsection{Circular motion lesson using EDP-STS- STEM model}

EDP strategy was adopted based on Yuenyong [1] [8]5-step STS approach to be implemented in the 5-week lesson of circular motion for 44 students in Grade 10. Students were asked to divide into groups to design the engineering of safety road that they feel safe to travel on.

In the first stage of EPD strategy, students were "challenged to solve the social issues" of car accidents occurred at the high bridge with sharp curve in Brazil that caused many deaths each year. Students started to identify the problem and potential solutions. They became aware of knowledge concerning circular motion in Physics, mathematical calculation and other related knowledge to be used in designing the safety road. Thus, during the engineering design process, students were observed on how they reflected their reasoning and critical thinking skills through their explanation. 
In the second stage of EDP strategy, students "researched" about formulas to be applied in circular motion calculation. They explained that various factors have influence on circular motion. Students mentioned that relationship among centripetal force, speed and velocity, radius, period, angle of slope cure, angular velocity, and acceleration must be in consideration to design a safety road for truck drivers that deliver massive weight passing the bridge at a sharp curve.

After group discussion activity, students perceived views of science and mathematics as foundation knowledge to "design solution" of an engineering invention. During this third stage of EDP, students must list their possible solutions, and select the best engineering solution to construct a safety road on the given worksheet.

Then, in the fourth stage of EDP strategy, students could evaluate their solution, or even "redesign" if the solution was tested and found with better solutions and fewer concerns. In the final stage of EDP strategy, students could share their best solution to the class, aiming to finalize their "decision-Making" to solve the car accident problem.

The findings indicated that students solved the car accident problems on the road more cooperatively by integrating calculation knowledge of Science and Mathematics combined with technological and engineering skills in their engineering design process through the innovative teaching strategy of EDP-STS-STEM Model.

\subsection{Electrical current lesson using EDP-STS- STEM model}

EDP strategy was adopted based on Yuenyong [1] [8]5-step STS approach to be implemented in the 6-week lesson of electrical current for 60 students in Grade 11. In the first stage of EPD strategy, students were "challenged to solve the social issues." By using the question: what if there is no longer electricity supplied for people and how to design electricity generation from clean energy, students became alert to identify the solutions and potential solutions.

In the second stage of EPD strategy, students started to conduct "research" of the knowledge concerning Ohm's law, resistance, electromotive force, transformer, circuit design, and electric generator as to design an engineering invention. Then, teacher provided lesson regarding wind energy by explaining the properties of forces that can generate electricity.

In the third stage of EPD strategy, students applied science and mathematics knowledge to "design a solution" of turbine model connected to an electricity generator. During this stage, students must draw their possible designs on the given worksheet along with explanation and select only the best design to be tested first.

In the final stage of EDP strategy of "decision-making", students were encouraged to evaluate the effectiveness of the turbine model before finalizing the solution of engineering design. After teacher allowed them to share ideas among groups, students came up with newer and greater design of a turbine model. Therefore, these findings implied that students reflected their learning from communication with others about their solution and redesign it if possible. Moreover, students learnt that innovative and critical skills as well as knowledge of science, technology, engineering and mathematics are needed to design an effective turbine model to generate electricity from clean energy to reduce environmental issues.

\subsection{Wave lesson using EDP-STS-STEM model}

EDP strategy was adopted based on Yuenyong [1] [8]5-step STS approach to be implemented in the 5-week lesson of wave for 50 students in Grade 11.

In the first stage of EPD strategy, students were "challenged to solve an environmental issue." By using the question: why is Tsunami wave so powerful that can destroy the whole city? Can we make use of wave? Students started to present the drawbacks of massive wave annihilating the city. However, after teacher showed them the video of Kinetic Wave Power Station, students became aware of benefits of wave that can generate electricity.

In the second stage of EDP, students should "research" more information of properties of wave. Then, teacher provided lesson of two types of wave: mechanical and electromagnetic and its four characters: reflection, diffraction, refraction, and interference. After learning the lessons, students came across the ideas to "design solutions" in the third stage of EDP strategy. Students learnt to draw an engineering 
design along with some explanation in each step before they designed the model of their solution.

Then, each group presented the design of using wave force to generate electricity to the class by explaining how the model worked, what problems they found in the design, and how to improve the design in the future to reduce complexity or errors and increase its effectiveness. After the presentation to the class, students constructed new knowledge from "communication" with other groups with different learning experience in order to "redesign" a more effective engineering solution to solve one particular problem as suggested in the fourth stage of EDP strategy.

By "testing and evaluating" the wave energy model in the final stage of EDP strategy by students themselves, rather than teacher, students would understand their own mistakes to be eliminated in their future. From students' presentation mentioning the flaws found during the testing process, it implied that learning activities through EDP strategy allowed students to explicit their learning experience to construct knowledge by integrating STS and STEM subjects to enhance their self-efficiency at their own pace.

\section{Conclusions}

In conclusion, according to the nature of STS approach which social scenarios were used as problems that students need to find the solutions in science classroom. Similarly, engineering design process was introduced into science classroom as "E" of STEM education. This study attempts to find a powerful learning strategy for STEM Education. Thus, the integration of STS approach and engineering design process was used in this study as STEM education pedagogy. The EDP-STS-STEM model provides more opportunities for students to solve social problems by reflect their scientific knowledge and critical skills in designing an engineering invention. In addition, teachers should hold opportunism to increase EDP insights more present in actual teaching, so that students can perceive social problems as challenges that motivate students' interest to enhance their self-learning in order to apply higher level scientific knowledge and innovative skills to solve the problem. From the findings, the EDP-STS-STEM teaching strategy is an adjustable and practical approach to be adopted in science class at all levels.

\section{Reference:}

[1] Baharin, N., Kamarudin, N., \&Manaf, U. K. A. Integrating STEM education approach in enhancing higher order thinking skills. International Journal of Academic Research in Business and Social Sciences, 8(7), 810-821. (2018).

[2] Marsono, M., Khasanah, F., \&Yoto, Y. Integrating STEM (Science Technology Engineering and Mathematics) Education on Advancing Vocational Student's Creative Thinking Skills. In 2nd International Conference on Vocational Education and Training (ICOVET 2018). Atlantis Press. (2019, January).

[3] Tupsai, J., \&Yuenyong, C. Investigating students' view on STEM in learning about electrical current through STS approach. In AIP Conference Proceedings (Vol. 1923, No. 1, p. 030054). AIP Publishing LLC. (2018, January).

[4] Tupsai, J., Bunprom, S., Saysang, J., \&Yuenyong, C. Students' Applying STEM Knowledge in Learning on the STS-STEM Education Wave Learning Unit. In Journal of Physics: Conference Series (Vol. 1340, No. 1, p. 012054). IOP Publishing. (2019, October).

[5] Bunprom, S., Tupsai, J., \&Yuenyong, C. Learning Activities to Promote the Concept of Engineering Design Process for Grade 10 Students' Ideas about Force and Motion through Predict-Observe-Explain (POE). In Journal of Physics: Conference Series (Vol. 1340, No. 1, p. 012081). IOP Publishing. (2019, October).

[6] Seattha, P., Tupsai, J., Sranamkham, T., \&Yuenyong, C. Students' view on STEM in learning about circular motion through STS approach. In AIP Conference Proceedings(Vol. 1775, No. 1, p. 030063). AIP Publishing LLC. (2016, October).

[7] Shukla, D., \&Dungsungnoen, A. P. Student's Perceived Level and Teachers' Teaching Strategies of Higher Order Thinking Skills: A Study on Higher Educational Institutions in Thailand. Journal of Education and Practice, 7(12), 2 11-219. (2016).

[8] Yuenyong, C., Jones, A., Sung-Ong, S., Yutakom, N., \&Forret, M. (2006). Teaching and Learning about Energy: Using Science, Technology and Society (STS) Approach. Kasetsart University.

[9] Attapan N \&Yuenyong C (2019). Explicit Nature of Science in the STS Contact Lens "Big Eyes" Unit. Journal of Physics: Conference Series, 1340 (1), 012066

[10] Boonprasert, L., Tupsai, J.\&Yuenyong, C. (2018). Grade 8 students' capability of analytical thinking and attitude toward science through teaching and learning about soil and its' pollution based on science technology and society (STS) approach. AIP Conference Proceedings. 1923, 030070-1 - 030070-8. (View online: https://doi.org/10.1063/1.5019561)

[11] Jimakorn, N., \&Yuenyong, C. (2018). Thai primary students' understanding of nature of science (NOS) in learning about force and motion for explicit NOS through STS approach. AIP Conference Proceedings. 1923, 030063-1 - 030063-7. (View online: https://doi.org/10.1063/1.5019554)

[12] Jumpatong, S. \&Yuenyong, C. (2018). Developing the STS sound pollution unit for enhancing students' applying knowledge among science technology engineering and mathematics. AIP Conference Proceedings. 1923, 030023-1 - 030023-7. 
[13] Luengam, P., Tupsai, J., \&Yuenyong, C. (2018). Grade 7 students' normative decision making in science learning about global warming through science technology and society (STS) approach. AIP Conference Proceedings. 1923, 030059-1 - 03005910. (View online: https://doi.org/10.1063/1.5019550)

[14] Ngaewkoodrua, N., \&Yuenyong, C. (2018). Teachers' learning on the workshop of STS approach as a way of enhancing inventive thinking skills. AIP Conference Proceedings. 1923, 030030-1 - 03003011. (View online: https://doi.org/10.1063/1.5019521)

[15] Nongkhunsarn A, Yuenyong C, Tupsai J, \&Sranamkam T. (2019). Grade 11 Student's Mental Model of Fluid and Analytical Thinking in Science Teaching Through Science Technology and Society (STS) Approach. Journal of Physics: Conference Series, 1340 (1), 012043

[16] Seattha, P., Tupsai, J., Sranamkham, T., \&Yuenyong, C. (2015). Developing STS projectile motion unit for providing students' perception of the relationship between science technology engineering and mathematics. Doctoral Student Consortium (DSC) -

\section{ISSN 2455-6378}

Proceedings of the 23rd International Conference on Computers in Education, ICCE 2015 pp. 488-496

[17] Seattha, P., Yuenyong, C., \& Art-in, S. (2015). Developing STS circular motion unit for providing students' perception of the relationship between science technology engineering and mathematics. Mediterranean Journal of Social Sciences, 6(3), 268275. (SCOPUS)

[18] Wongsila S. \&Yuenyong C. 2019. Enhancing Grade 12 Students' Critical Thinking and Problem-Solving Ability in Learning of the STS Genetics and DNA Technology Unit. Journal for the Education of Gifted Young Scientists, 7(2), 215-235

[19] Yuenyong C 2017 Enhancing Thai Students' Thinking Skills about Energy issues: Influence of Local Values. Chemistry: Bulgarian Journal of Science Education, 26 (3): 363 - 376

[20] [20]Yuenyong, C. 2019. Lesson learned of building up community of practice for STEM education in Thailand. AIP Conference Proceedings. 2081, 020002-1 - 020002-6. (https://doi.org/10.1063/1.5093997) 